\title{
Obstructive lesions of the genital tract in men
}

\author{
R. Y. Ball and M. J. Mitchinson \\ Department of Pathology, Tennis Court Road, Cambridge CB2 IQP, U.K.
}

\begin{abstract}
Summary. Obstructive lesions of the efferent and epididymal ducts in man were a common finding at necropsy. Although they demonstrated evidence of resorption of spermatozoa, they did not appear to be associated with the development of spermagglutinating antibodies in most cases. It is concluded that local spermiophagy within the genital tract in men is insufficient to lead to the development of antisperm autoallergy as detected by the tray agglutination test.
\end{abstract}

\section{Introduction}

Spermatozoa contain various antigens 'foreign' to the host but in health they are sequestered behind the blood-testis barrier and autoallergy does not develop (Johnson, 1973). Autoantibodies to spermatozoa are found in a small proportion of infertile men (Rümke \& Hellinga, 1959; Fjällbrant, 1968; Ansbacher, Manorang-Pangan \& Srivanraboon, 1971; Hjort \& Husted, 1975; Hendry, Morgan, Stedronska, Scammell \& Chamberlain, 1978) and are a common complication of vasectomy (Phadke \& Padukone, 1964; Zappi, Ahmed, Davis \& Shulman, 1970; Ansbacher, 1974; Alexander, Wilson \& Patterson, 1974; Tung, 1975; Hellema, Samuel \& Rümke, 1979). For antisperm autoallergy to develop in such circumstances implies that sperm antigens are able to stimulate appropriate lymphocytes, presumably as a result of incompetence of the blood-testis barrier. Alexander (1977) suggested three ways in which this might happen after vasectomy: (1) spillage of spermatozoa at the time of operation; (2) the production of spermatic granulomata; and (3) the resorption of spermatozoa trapped within ducts by lysis or phagocytosis by macrophages. Other factors, such as the genetic background (Bigazzi, Kosuda \& Harnick, 1977; Kosuda \& Bigazzi, 1978, 1979; Law, Bodmer, Mathews \& Skegg, 1979) and spermatolymphia (Ball, Naylor \& Mitchinson, 1982; Ball \& Setchell, 1983), may have a part to play.

Mitchinson, Sherman \& Stainer-Smith (1975) studied the epididymis at necropsy and revealed that obstruction of one or more efferent ducts was common. The present investigation was undertaken to throw further light on such lesions and to determine whether serological changes or abnormalities of the regional lymph nodes could be related to them.

\section{Materials and Methods}

Random cases were taken for study from among the necropsies performed on adult males at Addenbrooke's Hospital, Cambridge. The 54 subjects included patients who died in hospital and also a number of men on whom necropsy was ordered by H.M. Coroner. Ages ranged from 18 to 98 years (mean 58.8 years) and there was the expected preponderance of elderly subjects with a smaller peak in young adulthood as a result of accidents (Table 1). Ischaemic heart disease, trauma and pneumonia were the major causes of death, accounting for over half the cases. 
Table 1. Age distribution of the subjects studied

\begin{tabular}{cc}
\hline $\begin{array}{c}\text { Age range } \\
\text { (years) }\end{array}$ & $\begin{array}{c}\text { No. of } \\
\text { subjects }\end{array}$ \\
\hline $18-19$ & 4 \\
$20-29$ & 4 \\
$30-39$ & 2 \\
$40-49$ & 7 \\
$50-59$ & 6 \\
$60-69$ & 14 \\
$70-79$ & 9 \\
$>80$ & 8 \\
\hline
\end{tabular}

The testes and epididymides were obtained from all subjects and right and left para-aortic lymph node chains from 47 . All organs were fixed in $10 \%$ formal-saline, processed by standard techniques, embedded in paraffin wax and sections were cut $5 \mu \mathrm{m}$ thick. All sections were stained with haematoxylin and eosin and the following special stains were also used as appropriate: periodic acid-Schiff (PAS) after diastase digestion; modified Ziehl-Neelsen; Schmorl; Sudan black; oil-red-O; Masson Fontana; aldehyde fuchsin; toluidine blue; Martius scarlet blue; elastic Ponceau S; alcian blue; von Kossa; Perls' stain; Congo red; and Feulgen (Disbrey \& Rack, 1970). In most cases, serial transverse blocks, 1-2 mm thick, were cut through the caput epididymidis. The blocks were orientated before embedding so that sections were taken from their caudal surfaces. As indicated, additional levels were cut into these blocks at 50 -section intervals. Sections were also made of the corpus and cauda epididymidis, testis, rete testis and all para-aortic lymph nodes. Occasional specimens of the epididymis, showing no external abnormality, were cut longitudinally.

Blood was obtained at necropsy from 41 subjects; for 13 of these patients who had died in hospital it was also possible to acquire serum or plasma collected before death. The sera were stored at $-20^{\circ} \mathrm{C}$ and were then tested for antisperm antibodies using the tray agglutination test (Rose, Hjort, Rümke, Harper \& Vyazov, 1976). The test was performed on 4 occasions using semen, from different donors, with high sperm counts $\left(70-150 \times 10^{6} / \mathrm{ml}\right)$ and excellent motility. Control sera (head-to-head and tail-to-tail agglutinating and negative control) were kindly provided by $\mathrm{Mr} \mathrm{W}$. F. Hendry of St Bartholomew's Hospital, London.

\section{Results}

Testes

Normal testicular histology was present in 37 men. Sixteen men, mostly elderly, showed various degrees of testicular atrophy. The changes ranged from hyaline fibroelastic thickening of the tunica propria with associated aspermatogenesis to complete destruction of the tubules, which were replaced by shrunken, acellular, hyalinized ghosts. The only other significant testicular abnormality was hypospermatogenesis in a 19-year-old man.

\section{Efferent ducts}

One third of all epididymides showed evidence of obstruction of one or more of the efferent ducts. The age distribution of such lesions, "brown patches" (Mitchinson et al., 1975), spermatic granulomata and microscopic spermatocoeles is shown in Table 2. Obstructive lesions were seen in $7(21 \%)$ of the epididymides from men aged $<50$ years and in $29(39 \%)$ of those from older subjects. This difference is not significant $\left(\chi^{2}=3.63 ; 0.05<P<0.1\right)$. 
Table 2. Age distribution of obstructive lesions of the efferent ducts (men with spermatic granulomata or microscopic spermatocoeles often had "brown patches" of other efferent ducts)

\begin{tabular}{ccccc}
\hline $\begin{array}{c}\text { Age range } \\
\text { (years) }\end{array}$ & $\begin{array}{c}\text { No. of } \\
\text { epididymides }\end{array}$ & $\begin{array}{c}\text { No. with } \\
\text { "brown patches" }\end{array}$ & $\begin{array}{c}\text { No. with } \\
\text { spermatic } \\
\text { granulomata }\end{array}$ & $\begin{array}{c}\text { No. with } \\
\text { microscopic }\end{array}$ \\
\hline $18-19$ & 8 & 0 & 0 & 1 \\
$20-29$ & 8 & 2 & 1 & 2 \\
$30-39$ & 4 & 0 & 0 & 0 \\
$40-49$ & 14 & 0 & 1 & 0 \\
$50-59$ & 12 & 2 & 0 & 1 \\
$60-69$ & 28 & 8 & 3 & 2 \\
$70-79$ & 18 & 6 & 0 & 1 \\
$80+$ & 16 & 4 & 0 & 2 \\
Total & 108 & 22 & 5 & 9 \\
\hline
\end{tabular}

The "brown patches" were characterized by large numbers of pigmented macrophages in the interstitium (P1. 1, Fig. 1) associated with abnormalities of the efferent ducts but with no evidence of extravasation of spermatozoa. Such lesions were well-defined anatomically and affected one or more of the efferent ducts. The interstitial macrophages contained coarse granules of ceroidlipofuscin pigment (Pearse, 1972) but no recognizable spermatozoa. Such macrophages were usually found in large masses near dilated, abnormal segments of the ducts.

The efferent duct involved in a "brown patch" was abnormal in structure and contents. Its calibre ranged from considerable dilatation proximally (Pl. 1, Fig. 2) to severe narrowing or complete, fibrous obliteration distally. The narrowed segment was often surrounded by a thick, hyperplastic muscle coat. Dilated segments were lined by a cuboidal or flattened epithelium. The taller epithelial cells contained granules of pigment similar in staining reactions to that of the nearby interstitial macrophages. Pigmented macrophages, often in large numbers, were present between epithelial cells and usually adjacent to the basement membrane. Such cells did not contain recognizable spermatozoa. The lumina of the dilated tubules invariably contained large numbers of spermatozoa, many appearing normal morphologically, but others showing swollen heads and a loss of basophilia. Large clumps of agglutinated spermatozoa were often present (Pl. 1, Fig. 3). Many such masses were deeply basophilic and stained by the Feulgen and modified Ziehl-Neelsen methods. Others were eosinophilic and PAS-positive and failed to stain with Feulgen. Macrophages were often associated with these masses, being present within their depths or, more obviously, adherent to their surfaces. Not infrequently, clumps of agglutinated spermatozoa were present between the epithelium and its basement membrane, giving the impression that they had been excluded from the lumen by epithelial overgrowth (Pl. 1, Fig. 4). Also present within the dilated segments of obstructed efferent ducts were large, foamy, pigmented macrophages usually containing many phagocytosed spermatozoa (Pl. 2, Fig. 5) and, elsewhere, finely granular, eosinophilic debris associated with cholesterol clefts and free ceroid pigment granules.

Interstitial lymphocytes were sometimes conspicuous in "brown patches", often surrounding nearby vascular bundles in large numbers and scattered among the pigmented macrophages (Pl. 2, Fig. 6). Only rarely were they seen within the adjacent epithelium.

Spermatic granulomata were recognized among the efferent ducts in 5 epididymides, one of which was from the only man in the series who had been vasectomized (Pl. 2, Fig. 7). The lesions were small and comprised a few extravasated spermatozoa with an associated, well-defined mononuclear inflammatory exudate consisting of a dense mass of macrophages and epithelioid cells, sometimes with faintly pigmented or basophilic cytoplasm. Spermiophagy was conspicuous. Lymphocytes were present at the periphery. Although nearby lymphatic vessels contained lymphocytes and macrophages, none had spermatozoa within the lumen. 
Microscopic spermatocoeles were similar in appearance to the dilated part of the efferent duct in the "brown patch" but showed a greater degree of dilatation over a shorter length of the duct. The effect of this was to produce a single cyst with a simple, rounded, rather than convoluted, outline. The luminal contents were similar to those described for "brown patches".

\section{Epididymal and deferent ducts}

Pathological changes of the epididymal and deferent ducts were less common than those of the efferent ducts. The cauda epididymidis was affected most often. Interstitial spermatic granulomata were discovered in one cauda from each of 3 subjects, one aged 18 years and the other two in their sixties. The lesions were multiple. Some, considered relatively recent in origin, were similar in structure to those found among the efferent ducts but contained more spermatozoa and showed greater pigmentation of the macrophages. Other lesions thought to be older, showed masses of extravasated spermatozoa, often appearing normal histologically, surrounded by and mixed with dense fibrous connective tissue (Pl. 2, Fig. 8). Such lesions appeared healed and there was no evidence of continuing inflammation, despite the persistence of recognizable spermatozoa. The epididymal duct in these 3 subjects, and also in several others without spermatic granulomata, was dilated and its lumen contained masses of eosinophilic material demonstrating a granular or fibrillary appearance. Some ducts contained masses of agglutinated spermatozoa and luminal pigmented macrophages exhibiting spermiophagy. These features were identical to those seen in the efferent ducts.

\section{PLATE 1}

Fig. 1. Caput epididymidis from a 67-year-old man with typical "brown patches". The epithelium of an efferent duct is visible at the edge of the photograph. Macrophages containing coarse granules of PAS-positive pigment are present immediately outside the basement membrane and in the interstitium. PAS, $\times 300$.

Fig. 2. Caput epididymidis from a 67-year-old man. The efferent duct in the "brown patch" illustrated shows considerable dilatation. The lumen is full of pale, granular debris and occasional, darker aggregates of spermatozoa. $\mathrm{H} \& \mathrm{E}, \times 30$.

Fig. 3. Caput epididymidis from a 74-year-old man. A moderately dilated efferent duct contains many free spermatozoa as well as clumps of agglutinated spermatozoa, some remaining deeply basophilic (b) whilst others have become eosinophilic (e). H \& E, $\times 200$.

Fig. 4. Caput epididymidis from a 74-year-old man. A mass of aggregated spermatozoa has been excluded from the lumen of the duct by epithelial overgrowth, the original epithelium having disappeared. $\mathrm{H} \& \mathrm{E}, \times 200$.

\section{PLATE 2}

Fig. 5. Caput epididymidis from a 49-year-old man who had undergone vasectomy. Numerous large macrophages which have phagocytosed spermatozoa are present in the lumen. A similar appearance is seen in typical "brown patches". $\mathrm{H} \& \mathrm{E}, \times 300$.

Fig. 6. Caput epididymidis in a 67-year-old man. The interstitium in a "brown patch" contains numerous lymphocytes diffusely scattered among the pigmented macrophages. PAS, $\times 300$.

Fig. 7. Caput epididymidis from a 49-year-old man who had undergone vasectomy. An interstitial spermatic granuloma compresses one of the efferent ducts. The centre of the lesion consists of macrophages and epithelioid cells and a few phagocytosed sperm heads (arrow). Lymphocytes are conspicuous, especially at the periphery of the lesion. H \& E, $\times 200$.

Fig. 8. Cauda epididymidis in a 67-year-old man. Large masses of deeply basophilic, agglutinated spermatozoa are present in the interstitium and are surrounded by bands of dense mature collagen. A few lymphocytes are present but there is no evidence of continuing inflammation. $\mathrm{H} \& \mathrm{E}, \times 300$. 


\section{PLATE 1}
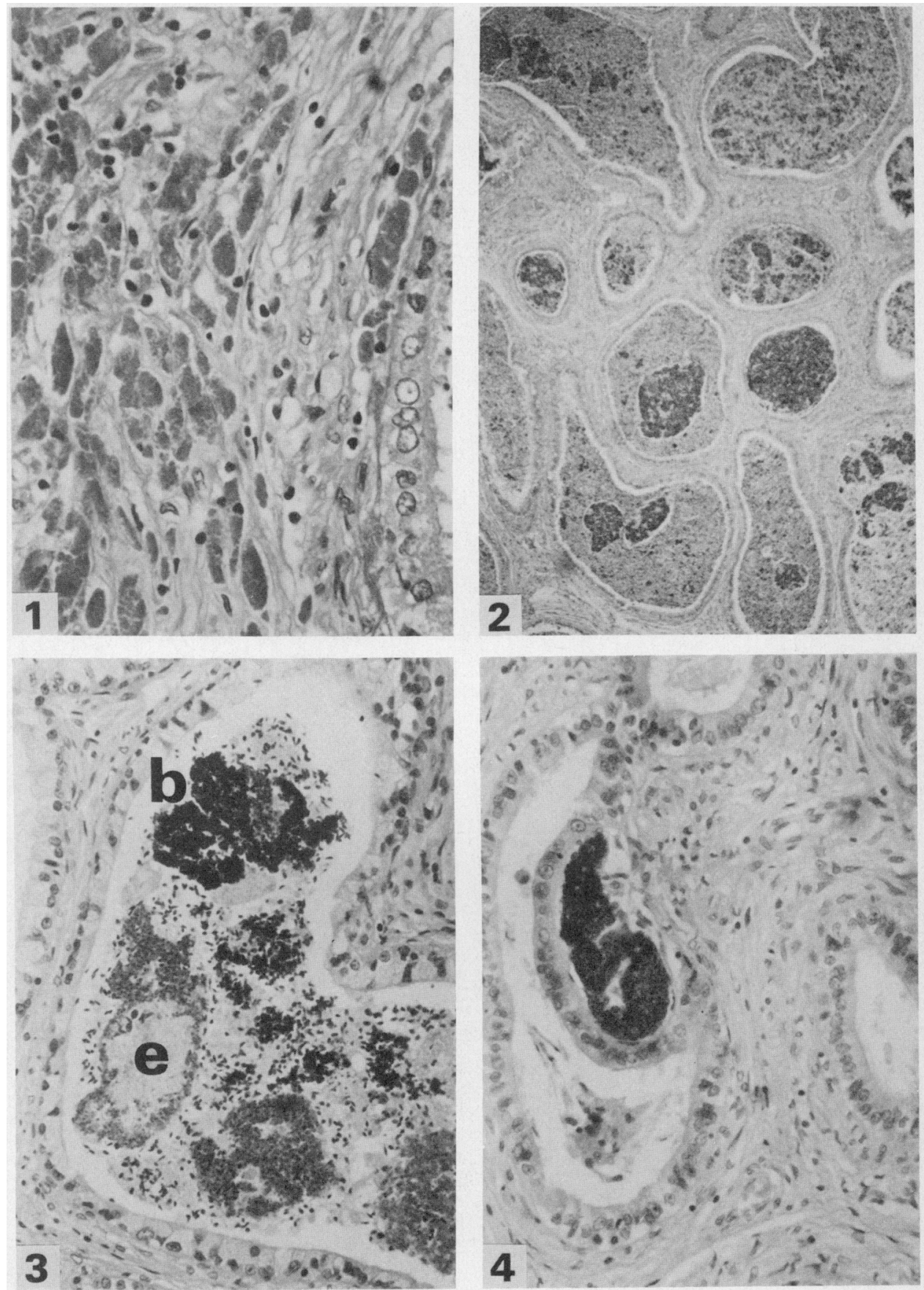
PLATE 2
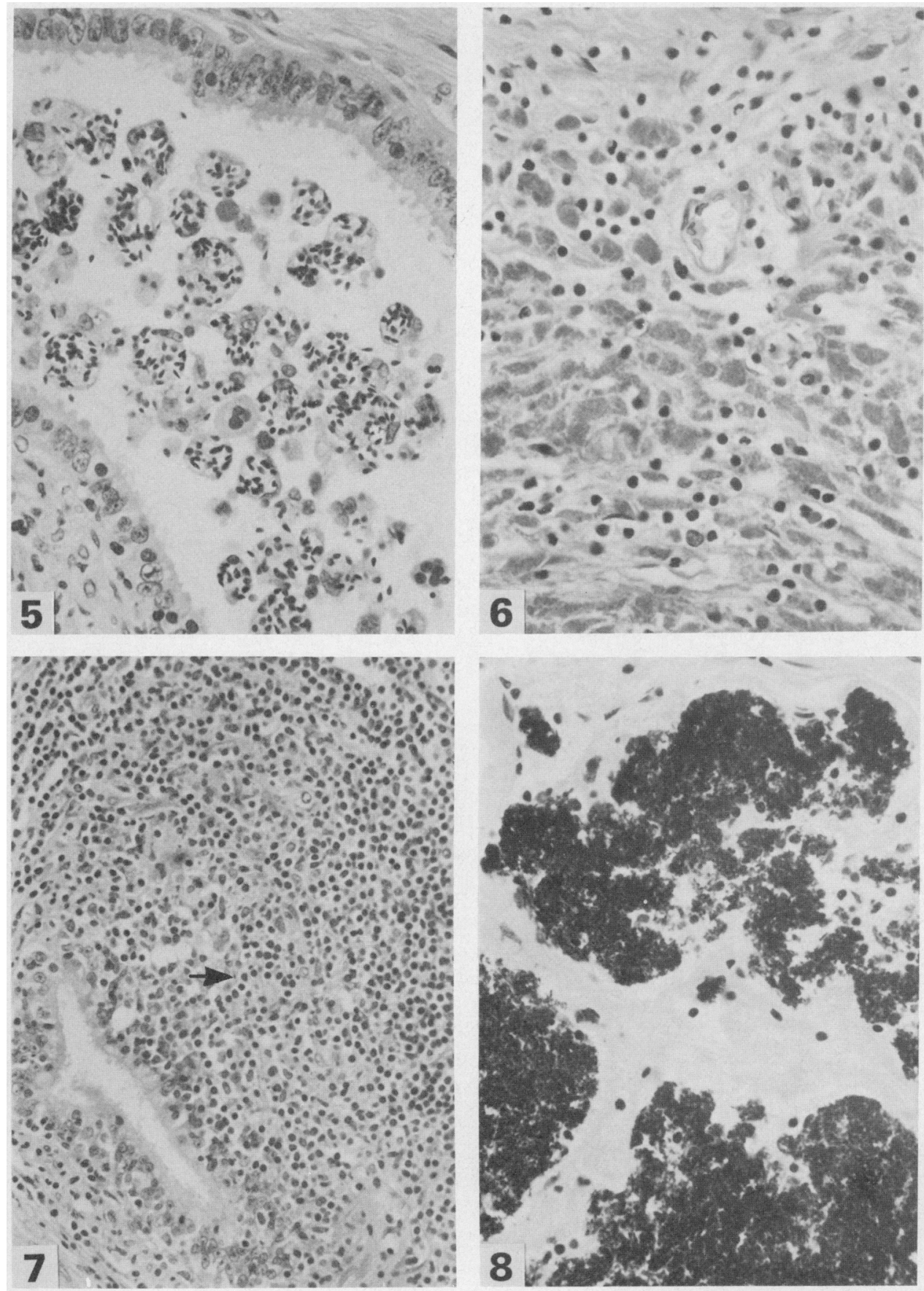
The deferent ducts of the subject who had been vasectomized showed typical foreign body reactions to the ligatures and conspicuous periductal infiltration by mononuclear cells, especially lymphocytes and plasma cells. No spermatic granulomata were present at the operation site and there were no changes of vasitis nodosa (Civantos, Lubin \& Rywlin, 1972).

\section{Lymph nodes}

None of the lymph nodes contained any features which could be related specifically to the genital tract. Spermatozoa were not recognized in any node, including those from men in whom spermatozoa had extravasated into the epididymal interstitium.

\section{Serological findings}

Only one serum sample contained spermagglutinins and was from the subject who had been vasectomized. It showed tail-to-tail agglutination with a titre of $1: 128$. None of the other test sera contained agglutinating antibodies.

\section{Discussion}

Obstructive lesions of the genital tract were a common finding. About one third of epididymides showed evidence of obstruction of one or more of the efferent ducts and some subjects demonstrated obstruction of the cauda epididymidis or proximal vas deferens. In these men evidence of the resorption of trapped spermatozoa included: the presence of luminal macrophages containing numerous phagocytosed sperm heads; interstitial spermatic granulomata with the phagocytosis of spermatozoa by the cells of the inflammatory infiltrate; and, possibly, the eosinophilic luminal debris, which may contain lysed spermatozoa. Any of these pathological processes could underlie the development of antisperm autoallergy. Once they have phagocytosed spermatozoa within the obstructed efferent duct ("brown patch"), macrophages appear to migrate back into the interstitium (Mitchinson et al., 1975) where they might present 'processed' sperm antigens to immunocompetent cells. Lymphocytes are, indeed, common in these foci. In interstitial spermatic granuloma formation the spermatozoa have penetrated the immunological barrier and may be able to lead to the induction of an allergic reaction either directly, or after spermatolymphia (Ball et al., 1982; Ball \& Setchell, 1983), or as a result of 'processing' by macrophages. Lysis of spermatozoa within an obstructed duct might release soluble antigens which could then penetrate into the interstitium.

Of the 54 subjects examined, serum was available from 41 . These included 4 of the 8 men with spermatic granulomata and a large number with "brown patches" and microscopic spermatocoeles. Despite the number of subjects demonstrating pathological resorption of spermatozoa, only one man had antibodies in his serum. He had been vasectomized and had a microscopic spermatic granuloma among the efferent ducts of one testis and showed intraluminal spermiophagy on both sides. Since the tray agglutination test is sensitive and reliable (Boettcher, Hjort, Rümke, Shulman \& Vyazov, 1977) it therefore seems that resorption of spermatozoa, either within the ducts or in interstitial spermatic granulomata, is not generally sufficient by itself to cause the development of agglutinating antibodies. Rümke (1972) detected spermagglutinins in 3 of 8 men who, when they died (up to $2 \frac{1}{2}$ years later), revealed evidence of sperm resorption. This relatively high incidence contrasts with the results presented in the present study and it is difficult to find an explanation. It might be argued that considerable changes may occur in serum antibodies after death. However, during the unavoidable delay between dying and necropsy, the bodies were refrigerated and, moreover, there was no discrepancy between the results obtained with post-mortem sera and those obtained during life. The explanation may lie in the fact that none of the regional lymph nodes 
contained spermatozoa. Perhaps phagocytosis of spermatozoa locally in the genital tract leads to the rapid loss of antigenicity and it is only when unphagocytosed spermatozoa reach regional lymph nodes that an autoallergic reaction can be generated. The lack of evidence of spermatolymphia in the one subject who did develop antisperm antibodies is not against this suggestion; the passage of spermatozoa within regional lymphatics is intermittent (Ball \& Setchell, 1983) and once an individual had developed a good secondary antibody response, high serum titres would persist for prolonged periods.

Of the 32 testes showing atrophy, 7 were related to prominent or major obstructive lesions (i.e. multiple "brown patches"; spermatic granulomata; or epididymal ductal obstruction). On the other hand, some subjects who had severe or total obstruction of the excurrent ducts (such as the man who had been vasectomized) showed normal testicular histology. Obstruction of the genital tract is, therefore, not necessarily associated with testicular atrophy in man, a finding in keeping with other observations (Nelson, 1952; Tillinger, 1957; Wong, Strauss \& Warner, 1973; Bigazzi, Alexander \& Silber, 1979). The testicular atrophy in 2 subjects could be attributed to chronic alcoholism and in a third to pelvic irradiation. In the remaining 13 the cause is elusive but agerelated deficiencies in the testicular microcirculation might be important (Sasano \& Ichijo, 1969; Suoranta, 1971).

The present study confirmed and extended the findings of Mitchinson et al. (1975). Careful examination of serial blocks through the caput epididymidis revealed that each "brown patch" or microscopic spermatocoele was derived from a single obstructed efferent duct. There was no evidence for these obstructions having their origin in congenitally blind-ending ducts but they appeared to be a result of previous inflammation. "Brown patches" and microspermatocoeles are a common lesion and not, apparently, age-related as has already been noted (Mitchinson et al., 1975). The present study shows that they do not lead to the production of antisperm antibodies. This is not surprising. If "brown patches" were involved in such autoallergy, the incidence of agglutinating antibodies in the general population would be much higher than it is.

Spermatic granulomata were found amongst the efferent ducts and in the cauda epididymidis in 8 subjects. The incidence of such lesions ( $7.4 \%$ of epididymides) is greater than that reported by Sundarasivarao (1955), suggesting that small spermatic granulomata are, like "brown patches", a common abnormality. The appearances of the granulomata were similar to those described by Glassy \& Mostofi (1956).

In conclusion, this study has shown that obstructive lesions of the genital tract are common in man and that the response to obstructed or extravasated spermatozoa is phagocytosis by macrophages. The incidence of antisperm antibodies, as detected by the tray agglutination test, does not reflect the prevalence of such lesions. It therefore appears that local phagocytosis of spermatozoa is an effective means of destroying their allergenicity. Further work is required to elucidate the nature of the afferent arm of the allergic reaction to sperm antigens.

R.Y.B. is funded by an Elmore Medical Research Studentship and St John's College, Cambridge. We thank Mr A. King and his staff for processing the specimens for histology, Mr W. F. Hendry for control sera and Mrs Helen Wilson and Mrs Margaret Bradley for typing the manuscript.

\section{References}

Alexander, N.J. (1977) Immunological aspects of vasectomy. In Immunological Influence on Human Fertility, pp. 25-46. Ed. B. Boettcher. Academic Press, Sydney.

Alexander, N.J., Wilson, B.J. \& Patterson, G.D. (1974) Vasectomy: immunological effects in rhesus monkeys and men. Fert. Steril. 25, 149-156.
Ansbacher, R. (1974) Bilateral vas ligation: sperm antibodies. Contraception 9, 227-237.

Ansbacher, R., Manorang-Pangan, S. \& Srivanraboon, S. (1971) Sperm antibodies in infertile couples. Fert. Steril. 22, 298-302.

Ball, R.Y. \& Setchell, B.P. (1983) The passage of spermatozoa to regional lymph nodes in testicular Downloaded from Bioscientifica.com at 04/26/2023 01:59:17PM via free access 
lymph following vasectomy in rams and boars. $J$. Reprod. Fert. 68, 145-153.

Ball, R.Y., Naylor, C.P.E. \& Mitchinson, M.J. (1982) Spermatozoa in an abdominal lymph node after vasectomy in a man. $J$. Reprod. Fert. 66, 715-716.

Bigazzi, P.E., Kosuda, L.L. \& Harnick, L.L. (1977) Sperm autoantibodies in vasectomized rats of different strains. Science, N.Y. 197, 1282-1283.

Bigazzi, P.E., Alexander, N. J. \& Silber, S.J. (1979) Studies on testicular biopsies from vasectomized men. In Vasectomy. Immunologic and Pathophysiologic Effects in Animals and Man, Ch. 21, pp. 459-469. Eds I. H. Lepow \& R. Crozier. Academic Press, New York.

Boettcher, B., Hjort, T. Rümke, P., Shulman, S. \& Vyazov, O.E. (Eds) (1977) Auto- and iso-antibodies to antigens of the human reproductive system. I. Results of an international comparative study. (W.H.O. Reference Bank for Reproductive Immunology.) Clin. exp. Immunol. 30, 173-180.

Civantos, F., Lubin, J. \& Rywlin, A.M. (1972) Vasitis nodosa. Archs Path. 94, 355-361.

Disbrey, B.D. \& Rack, J.H. (1970) Histological Laboratory Methods. Livingstone, Edinburgh.

Fjällbrant, B.O. (1968) Sperm antibodies and sterility in men. Acta obstet. gynecol. scand. 47, Suppl. 4.

Glassy, F.J. \& Mostofi, F.K. (1956) Spermatic granulomas of the epididymis. Am. J. clin. Path. 26, 13031313.

Hellema, H.W.J., Samuel, T. \& Rümke, P. (1979) Sperm antibodies as a consequence of vasectomy. II. Longterm follow up studies. Clin. exp. Immunol. 38, 31-36.

Hendry, W.F., Morgan, H. Stedronska, J., Scammell, G. \& Chamberlain, C.V.P. (1978) The clinical significance of antisperm antibodies in male subfertility: crossed hostility testing and prednisolone treatment. In Spermatozoa, Antibodies and Infertility, ch. 11, pp. 129-137. Eds J. Cohen \& W. F. Hendry. Blackwell, Oxford.

Hjort, T. \& Husted, S. (1975) Autoimmunity to sperm. Proc. R. Soc. Med. 68, 253-255.

Johnson, M.H. (1973) Physiological mechanisms for the immunological isolation of spermatozoa. In Advances in Reproductive Physiology, Vol. 6, ch. 6, pp. 279-324. Ed. M. W. H. Bishop. Elek Science, London.

Kosuda, L.L. \& Bigazzi, P.E. (1978) Autoantibodies to acrosomal antigens of spermatozoa in vasectomized mice. Invest. Urol. 16, 140-141.

Kosuda, L.L. \& Bigazzi, P.E. (1979) Influence of genetic factors on the production of autoantibodies to spermatozoa in vasectomized rats and mice of different inbred strains. In Vasectomy. Immunologic and Pathophysiologic Effects in Animals and Man, ch.
14, pp. 289-300. Eds I. H. Lepow \& R. Crozier, Academic Press, New York.

Law, H.Y., Bodmer, W.F., Mathews, J.D. \& Skegg, D.C.G. (1979) The immune response to vasectomy and its relation to the HLA system. Tissue Antigens 14, $115-139$.

Mitchinson, M.J., Sherman, K.P. \& Stainer-Smith, A.M. (1975) Brown patches in the epididymis. J. Path. 115, $57-62$.

Nelson, W.O. (1952) Spermatogenesis in testes of men with blocked or absent efferent ducts. In Studies on Testis and Ovary, Eggs and Sperm, pp. 2-25. Ed. E. T. Engle. C.C. Thomas, Springfield.

Pearse, A.G.E. (1972) Histochemistry. Theoretical and Applied, 3rd edn. Churchill, Edinburgh.

Phadke, A.M. \& Padukone, K. (1964) Presence and significance of autoantibodies against spermatozoa in the blood of men with obstructed vas deferens. $J$. Reprod. Fert. 7, 163-170.

Rose, N.R., Hjort, T., Rümke, P., Harper, M.J.K. \& Vyazov, O. (Eds) (1976) Techniques for the detection of iso- and auto-antibodies to human spermatozoa. Clin. exp. Immunol. 23, 175-199.

Rümke, P. (1972) Autoantibody formation against spermatozoa caused by extravasation of spermatozoa into the interstitium of the epididymis of aged men. Int. J. Fertil. 17, 86-88.

Rümke, P. \& Hellinga, G. (1959) Autoantibodies against spermatozoa in sterile men. Am. J. clin. Path. 32, 357363.

Sasano, N. \& Ichijo, S. (1969) Vascular patterns of the human testis with special reference to its senile changes. J. exp. Med. (Tohoku) 99, 269-280.

Sundarasivarao, D. (1955) Spermatozoal granuloma of the epididymis. J. Pathol. Bacteriol. 69, 324-326.

Suoranta, H. (1971) Changes in the small blood vessels of the adult human testis in relation to age and to some pathological conditions. Virchow's Archiv. 362, 165181.

Tillinger, K.-G. (1957) Some histological findings in testicles with blocked excretory ducts. Acta path. microbiol. scand. 41, 213-218.

Tung, K.S.K. (1975) Human sperm antigens and antisperm antibodies. I. Studies on vasectomy patients. Clin. exp. Immunol. 20, 93-104.

Wong, T.W., Strauss, F.H. \& Warner, N.E. (1973) Testicular biopsy in the study of male infertility. II. Post-testicular causes of infertility. Archs Path. 95, 160-163.

Zappi, E., Ahmed, V., Davis, J. \& Shulman, S. (1970) Immunologic consequences of vasectomy. Fedn Proc. Fedn Am. Socs. exp. Biol. 29, 374.

Received 12 September 1983 